$07,14,17$

\title{
Сравнительный анализ эффективности углеродных нанотрубок и графена в армированнии полимерных нанокомпозитов
}

\author{
(ㄷ Г.В. Козлов, И.В. Долбин ॠ \\ Кабардино-Балкарский государственный университет им. Х.М. Бербекова, \\ Нальчик, Россия \\ ฯ E-mail: i_dolbin@mail.ru \\ Поступила в Редакцию 8 апреля 2020 г. \\ В окончательной редакции 8 апреля 2020 г. \\ Принята к публикации 11 апреля 2020 г.
}

\begin{abstract}
Выполнен сравнительный анализ эффективности армирования (повышения модуля упругости) полимеров углеродными нанотрубками и графеном с использованием методов фрактального анализа и теории перколяции. Показано, что такое сравнение является корректным только при одинаковой структуре указанных анизотропных нанонаполнителей в полимерной матрице. Для углеродных нанотрубок эффективность армирования сильно зависит от их геометрии, т. е. длины и наружного диаметра. При этом основную роль в армировании полимеров играют не исходные характеристики нанонаполнителя, а полученные его структуры в процессе изготовления нанокомпозитов. В технологическом аспекте углеродные нанотрубки более пригодны для получения высокомодульных нанокомпозитов, что обусловлено возможностью достаточно простой реализации их ориентации.
\end{abstract}

Ключевые слова: нанокомпозит, углеродные нанотрубки, графен, степень усиления, фрактальная размерность, теория перколяции.

DOI: 10.21883/FTT.2020.08.49608.078

\section{1. Введение}

Разработка композитных материалов в настоящее время является одним из наиболее эффективных способов повышения качества полимеров и находит свое применение в наиболее инновационных областях промышленности: авиа- и автомобилестроении, космонавтике и т.п. $[1,2]$. В силу своей уникальной структуры и выдающихся механических, электрических, термических и оптических свойств углеродные нанотрубки (УНТ) и графены (Гр) являются основными кандидатами для использования в качестве нанонаполнителя для полимерных нанокомпозитов [3]. Однако, получение нанокомпозитов высокого качества часто затруднено как физикохимическими, так и технологическими причинами, к которым следует отнести изготовление этого класса наноматериалов, контроль их структуры и взаимодействия с полимерной матрицей [3]. В настоящее время технологические достижения в этой области явно опережают чисто научные результаты [4-6]. Это делает необходимым теоретический анализ реализации нанокомпозитов полимер/УНТ и полимер/Гр высокого качества, одной из составляющих которого является сравнение эффективности указанных нанонаполнителей в качестве армирующего элемента их структуры. В настоящее время существует несколько работ, представивших экспериментальное сравнение зависимостей степени усиления нанокомпозитов на основе эпоксидного полимера и полиэтилена с одинаковым содержанием углеродных нанотрубок и графена $[3,7,8]$. Результаты этого сравнения показали преимущество графена в этом отношении. Однако, произвольный выбор характеристик нанонаполнителя и отсутствие теоретического анализа полученных экспериментальных результатов не позволяет сделать окончательный вывод об их эффективности. Поэтому целью настоящей работы является теоретический анализ указанной эффективности углеродных нанотрубок и графена на примере нанокомпозитов на основе полиэтилена высокой плотности, наполненных этими анизотропными нанонаполнителями [8].

\section{2. Результаты и обсуждение}

В настоящей работе выполнен теоретический анализ экспериментальных данных, полученных в работе [8], для нанокомпозитов на основе полиэтилена высокой плотности (ПЭВП) - ПЭВП/УНТ и ПЭВП/Гр. В качестве матричного полимера использован промышленный ПЭВП марки Hostalen ACP 5831D, поставленный фирмой Lyondell Basell Indystries (Франция). В качестве нанонаполнителей применялись многослойные углеродные нанотрубки (МУНТ) с наружным диаметром 10-15 nm и средней длиной $\sim 4 \mathrm{mcm}$, а также графен, полученный из природного графита по методу Хаммерса [9], состоящем в следующей процедуре. Вначале графит окислялся концентрированной серной кислотой и перманганатом калия до оксида графена, который в форме водной суспензии обрабатывался ультразвуком в течении часа для эсфолиации его листов. Графен был получен восстановлением его оксида гидратом гидразина в течение одного h при температуре $368 \mathrm{~K}$ [8]. 
Нанокомпозиты ПЭВП/УНТ и ПЭВП/Гр приготовлены смешиванием компонент в расплаве на лабораторном двухшнековом смесителе марки Haake Minilab-II, производства ФРГ, в течение 10 min при температуре $463 \mathrm{~K}$ и скорости вращения шнека 150 turn $/ \mathrm{min}$. Каждая серия рассматриваемых нанокомпозитов содержала 0.5 , 1.0 и 3.0 mass\% нанонаполнителя (УНТ или Гр). Образцы для испытаний получены горячим прессованием при температуре $463 \mathrm{~K}[8]$.

Испытания на растяжение образцов нанокомпозитов ПЭВП/УНТ и ПЭВП/Гр выполнены на тензометре Instron 88215 на образцах в форме двойной лопатки с базовой длиной 25 , шириной 5 и толщиной $2 \mathrm{~mm}$ при скорости ползуна $10 \mathrm{~mm} / \mathrm{min}$ и температуре $295 \mathrm{~K}$ согласно стандарту ISO 527-3. За результат измерения принималось среднее арифметическое пяти испытаний [8].

Как упоминалось выше, в работах $[3,7,8]$ были получены более высокие показатели для нанокомпозитов ПЭВП/Гр по сравнению с ПЭВП/УНТ. Это различие было приписано более высокой удельной поверхности и большему аспектному отношению Гр по сравнению с УНТ $[3,78]$. Более того, в основу такого различия положена разная исходная топология МУНТ и Гр если первые являются одномерным (1D-) нанонаполнителем, то второй - двухмерным (2D-). Такой подход в своей основе является микромеханическим, т.е. учитывающим только характеристики исходного нанонаполнителя. Однако, в реальных полимерных нанокомпозитах топология нанонаполнителя существенно изменяется, и в первую очередь этот эффект обусловлен взаимодействиями нанонаполнитель-полимерная матрица и частиц нанонаполнителя между собой. К тому же, как правило, нанокомпозиты усиливаются не отдельными наночастицами, а их агрегатами [1]. Так, авторы [10] выполнили расчет фрактальной размерности МУНТ $D_{f}$ для нанокомпозитов полиметилметакрилат/МУНТ и обнаружили, что величина $D_{f}$ изменяется в интервале 1.70-2.14 при номинальной размерности МУНТ $D_{f}=1.0$, что примерно равно номинальной размерности графена $D_{f}=2.0[1]$.

С учетом вышесказанного была выполнена оценка размерности $D_{f}$ агрегатов МУНТ и Гр для рассматриваемых нанокомпозитов согласно следующему уравнению [11]:

$$
D_{f}=\frac{d\left(2 D_{f}^{m}-D_{f}^{n n}\right)}{d+2\left(D_{f}^{m}-D_{f}^{n a m}\right)},
$$

где $D_{f}^{m}$ и $D_{f}^{n a n}-$ размерности макромолекулярного клубка полимерной матрицы и исходной частицы нанонаполнителя $\left(D_{f}^{n a n}=1\right.$ для УНТ и $D_{f}^{n a n}=2$ для Гр $)$, соответственно, $d$ - размерность евклидова пространства, в котором рассматривается фрактал (очевидно, в нашем случае $d=3$ ). Величина $D_{f}^{m}$ принята равной 1.60 [12].

Оценки согласно уравнению (1) показали, что для УНТ $D_{f}=1.69$ и для Гр $D_{f}=1.92$. Это означает, что реальные величины $D_{f}$ существенно отличаются от номинальных и величина $D_{f}$ для УНТ меньше, чем

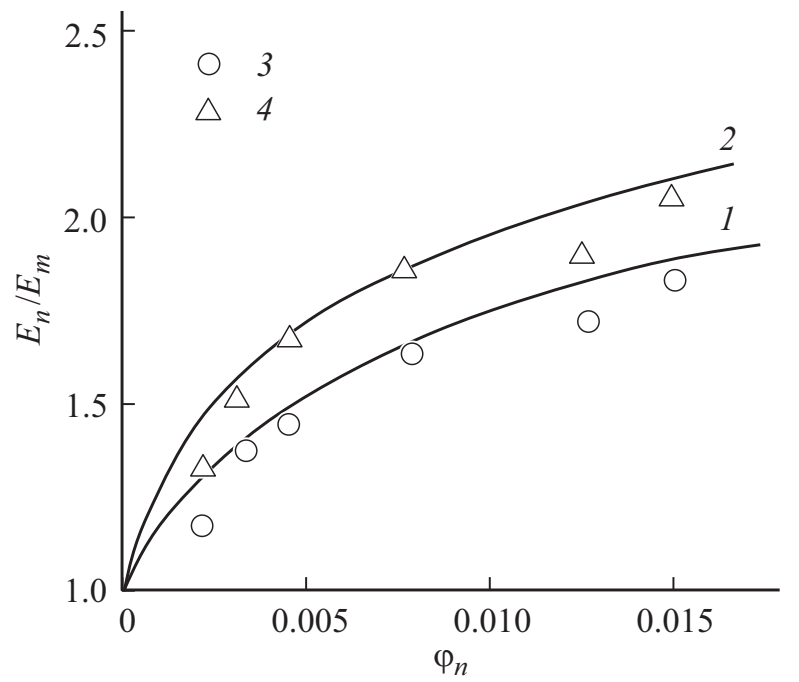

Рис. 1. Зависимости степени усиления $E_{n} / E_{m}$ от объемного содержания нанонаполнителя $\varphi_{n}$, рассчитанные согласно уравнениям (1) и (2) $(1,2)$ и полученные экспериментально $(3,4)$ для нанокомпозитов ПЭВП/МУНТ $(1,3)$ и ПЭВП/Гр $(2,4)$.

для Гр и это обстоятельство полностью обусловлено различием исходных (номинальных) размерностей рассматриваемых нанонаполнителей. Для оценки механических свойств нанокомпозитов можно использовать следующее фрактальное соотношение [13]:

$$
\frac{E_{n}}{E_{m}}=1+11\left(\varphi_{n}\right)^{1 D_{f}},
$$

где $E_{n}$ и $E_{m}-$ модули упругости нанокомпозита и матричного полимера, соответственно (отношение $E_{n} / E_{m}$ принято называть степенью усиления нанокомпозита), $\varphi_{n}$ - объемное содержание нанонаполнителя.

Величину $\varphi_{n}$ можно определить согласно следующей известной формуле [10]:

$$
\varphi_{n}=\frac{W_{n}}{\rho_{n}},
$$

где $W_{n}$ - массовое содержание нанонаполнителя, $\rho_{n}-$ его плотность, которая для УНТ и Гр принята равной $1600 \mathrm{\kappa g} / \mathrm{m}[8]$.

На рис. 1 приведено сравнение рассчитанных согласно уравнению (2) и полученных экспериментально зависимостей $E_{n} / E_{m}\left(\varphi_{n}\right)$ для рассматриваемых нанокомпозитов, которое показало их хорошее соответствие (среднее расхождение теории и эксперимента составляет $7.2 \%$ ). Таким образом, хотя различие реальных величин $D_{f}$ и не является таким большим, как номинальных, но именно различие последних определяет реальные значения $D_{f}$ и, следовательно, величины степени усиления $E_{n} / E_{m}$.

Отметим, что характеристики нанонаполнителей для рассматриваемых нанокомпозитов выбраны довольно произвольно. Так, на свойства нанокомпозитов полимер/УНТ, равно как и других полимерных нанокомпозитов, решающее влияние оказывает структура нанонаполнителя в полимерной матрице, которая в случае 
углеродных нанотрубок определяется их геометрией, т. е. диаметром и длиной [14]. Этот аспект можно исследовать в рамках молекулярной концепции усиления, основным соотношением которой является следующее уравнение [15]:

$$
\frac{E_{n}}{E_{m}}=1+c D_{n}^{m} W_{n}^{n} l_{s t}
$$

где $c$ - коэффициент, $m$ и $n-$ показатели, $D_{n}-$ базовый размер исходной частицы нанонаполнителя, $l_{s t}$ - длина статистического сегмента цепи полимерной матрицы, характеризующая ее гибкость.

Для каждого класса полимерных нанокомпозитов значения $n, m$ и $n$ являются константами и имеют следующие значения: для нанокомпозитов полимер/углеродные нанотрубки (в общем случае полимер/1D-нанонаполнитель) $c=0.05, m=0.50$ и $n=0.25$; для нанокомпозитов полимер/графен (в общем случае полимер/2D-нанонаполнитель) $c=0.32, m=0$ и $n=0.50$ [15]. В уравнении (4) используются следующие единицы измерения: коэффициент с является безразмерным параметром, $D_{n}$ и $l_{s t}$ даются в нанометрах $(\mathrm{nm}), W_{n}-$ в массовых процентах $(\operatorname{mass} \%)$. Далее можно записать общее соотношение (4) раздельно применительно к нанокомпозитам полимер/УНТ и полимер/Гр соответственно

$$
\frac{E_{n}}{E_{m}}=1+0.05 D_{\mathrm{CNT}}^{0.5} W_{n}^{0.25} l_{s t},
$$

и

$$
\frac{E_{n}}{E_{m}}=1+0.32 W_{n}^{0.5} l_{s t} .
$$

Из сравнения уравнений (5) и (6) следует, что в случае одинаковых матричного полимера и содержания нанонаполнителя можно получить следующее соотношение, которое определяет диаметр углеродной нанотрубки $D_{\mathrm{CNT}}^{e q}$, при котором достигается одинаковая степень усиления $E_{n} / E_{m}$ для нанокомпозитов рассматриваемых классов

$$
D_{\mathrm{CNT}}^{e q}=\left(6.4 W_{n}^{0.25}\right), \mathrm{nm} .
$$

Уравнение (7) демонстрирует, что при малых значениях $W_{n}$ порядка 1 mass $\%$, равенство армирующих способностей углеродных нанотрубок и графена может быть достигнуто использованием УНТ небольшого диаметра (порядка $40 \mathrm{~nm}$ ), типичного для отдельной нанотрубки [1], но при больших $W_{n}$ с этой же целью необходимо использование жгутов (пучков) УНТ большого диаметра. Так, при $W_{n}=50$ mass $\%$ величина достигает $\sim 290 \mathrm{~nm}$. На рис. 2 приведено сравнение полученных экспериментально и рассчитанных согласно уравнению (4) зависимостей $E_{n} / E_{m}\left(W_{n}\right)$ для нанокомпозитов ПЭВП/МУНТ и ПЭВП/Гр, которое показало их хорошее соответствие при среднем расхождении теории и эксперимента $8.1 \%$. На этом же рисунке показана аналогичная зависимость для нанокомпозита ПЭВП/МУНТ, рассчитанная согласно уравнению (5) при условии $D_{\mathrm{CNT}}=50 \mathrm{~nm}$. Как можно видеть, переход от

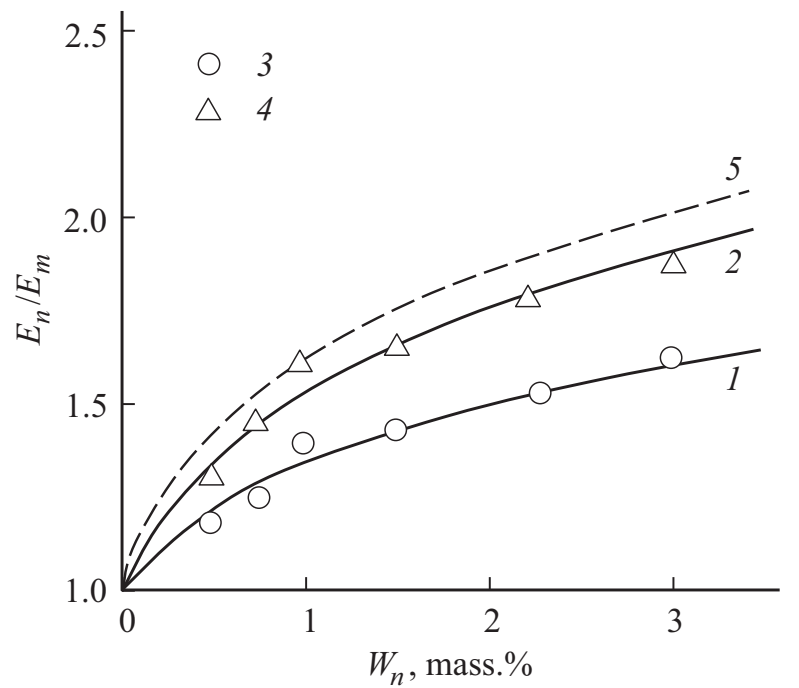

Рис. 2. Зависимости степени усиления $E_{n} / E_{m}$ от массового содержания нанонаполнителя $W_{n}$, рассчитанные согласно уравнению (4) и $(2)(1,2)$ и полученные экспериментально $(3,4)$ для нанокомпозитов ПЭВП/МУНТ $(1,3)$ и ПЭВП/Гр $(2,4)$. Кривая 5 - теоретическая зависимость $E_{n} / E_{m}\left(W_{n}\right)$, рассчитанная согласно уравнению (5) при гипотетическом условии $D_{\mathrm{CNT}}=50 \mathrm{~nm}$.

МУНТ диаметром $15 \mathrm{~nm}$ к МУНТ диаметром $50 \mathrm{~nm}$ дает возможность получить усиление МУНТ более эффективное, чем в случае графена. Отметим, что современные методы создания высокомодульных нанокомпозитов полимер/УНТ предполагают получение именно таких жгутов УНТ при больших $W_{n}[3-6]$.

Наиболее строго предложенная трактовка выражена в работе [16], где предложено следующее уравнение

$$
\frac{E_{n}}{E_{m}}=1+17 D_{f}^{2} \varphi_{n}
$$

которое показано корректным для трех основных классов полимерных нанокомпозитов: дисперсно-наполненных (0D-нанонаполнитель), полимер/углеродные нанотрубки (1D-нанонаполнитель) и полимер/графен или полимер/органоглина (2D-нанонаполнитель).

И в заключение отметим важное различие в технологии применения углеродных нанотрубок и графена. В силу одномерной природы исходных нанотрубок они могут легко ориентироваться и формировать жгуты (ленты), для чего существует ряд способов [3], а важность этого аспекта показана выше. На примере нанокомпозитов бисмалеимид/УНТ экспериментально продемонстрировано, что деформация жгутов УНТ (вытяжка) от 0 до $12 \%$ дает увеличение модуля упругости этих нанокомпозитов от 118 до $293 \mathrm{GPa}$, т.е. примерно в 2.5 раза, причем последняя величина En соответствует этому показателю для стали. В то же время аналогичная ориентация гибких листов графена оказалась достаточно проблематичной [3]. 


\section{3. Заключение}

Таким образом, результаты настоящей работы продемонстрировали, что для создания высокомодульных и высокопрочных нанокомпозитов полимер/углеродные нанотрубки и полимер/графен важны не исходные характеристики нанонаполнителя, а формирование его структуры в полимерной матрице нанокомпозита. Сравнивать нанокомпозиты полимер/углеродные нанотрубки и полимер/графен корректно только при одинаковой структуре нанонаполнителя, характеризуемой ее фрактальной размерностью $D_{f}$. Различие между рассматриваемыми нанонаполнителями состоит только в технологических аспектах создания такой структуры. В этом отношении преимущество имеют углеродные нанотрубки, которые в силу своей одномерной исходной структуры гораздо легче поддаются действию ориентационных технологий по сравнению с графеном.

\section{Конфликт интересов}

Авторы заявляют, что у них нет конфликта интересов.

\section{Список литературы}

[1] D.W. Schaefer, R.S. Justice. Macromol. 40, 8501 (2007).

[2] H. Kim, A.A. Abdala, C.W. Macosko. Macromol. 43, 6515 (2010).

[3] X. Sun, H. Sun, H. Li, H. Peng. Adv. Mater. 25, 5153 (2013).

[4] Q.F. Cheng, J.P. Wang, J.J. Wen, C.H. Liu, K.L. Jiang, Q.Q. Li, S.S. Fan. Carbon 48, 260 (2010).

[5] K. Kobashi, H. Nishino, T. Yamada, D.N. Futaba, M. Yumura, K. Hata. Carbon 49, 5090 (2011).

[6] X. Wang, Z.Z. Yong, Q.W. Li, P.D. Bradford, W. Liu, D.S. Tucker, W. Cai, H. Wang, F.G. Yuan, Y.T. Zhu. Mater. Res. Lett. 1, 19 (2013).

[7] M. Martin-Gallego, M.M. Bernal, M. Hernandez, R. Verdejo, M.A. Lopez-Manchado. Eur. Polymer J. 49, 1347 (2013).

[8] M. El Achaby, A. Qaiss. Mater. Des. 44, 81 (2013).

[9] W.S. Hummers, R.E. Offeman. J. Am. Chem. Soc. 80, 1339 (1958).

[10] Л.Б. Атлуханова, Г.В. Козлов, И.В. Долбин. Зав. лаборатория. Диагностика материалов 85, 43 (2019).

[11] H.G.E. Hentschel, J.M. Deutch. Phys. Rev. A 29, 1609 (1984).

[12] G.V. Kozlov, I.V. Dolbin, G.E. Zaikov. The Fractal Physical Chemistry of Polymer Solutions and Melts. Apple Academic Press, Toronto, New Jersey (2014). 316 p.

[13] L.B. Atlukhanova, G.V. Kozlov, I.V. Dolbin. Inorganic Mater.: Appl. Res. 11, 188 (2020).

[14] А.К. Микитаев, Г.В. Козлов. ДАН 462, 41 (2015).

[15] Г.В. Козлов, И.В. Долбин. Вестн. машиностроения 3, 77 (2019).

[16] Г.В. Козлов, П.Г. Ризванова, И.В. Долбин, Г.М. Магомедов. Изв. вузов. Физика 62, 112 (2019).

Редактор Т.Н. Василевская 